\title{
$\mathrm{PRISM}$ 을 이용한 $30 \mathrm{~m}$ 해상도의 상세 일별 기온 추정
}

\author{
안중배 · 허지나* - 임아영 \\ 부산대학교 지구환경시스템학부
}

(접수일: 2013년 10월 16일, 수정일: 2013년 11월 19일, 게재확정일: 2013년 12월 4일)

\section{Estimation of Fine-Scale Daily Temperature with 30 m-Resolution Using PRISM}

\author{
Joong-Bae Ahn, Jina Hur*, and A-Young Lim \\ Division of Earth Environmental System, Pusan National University, Busan, Korea
}

(Manuscript received 16 October 2013; accepted 4 December 2013)

\begin{abstract}
This study estimates and evaluates the daily January temperature from 2003 to 2012 with 30 m-resolution over South Korea, using a modified Parameter-elevation Regression on Independent Slopes Model (K-PRISM). Several factors in K-PRISM are also adjusted to $30 \mathrm{~m}$ grid spacing and daily time scales. The performance of K-PRISM is validated in terms of bias, root mean square error (RMSE), and correlation coefficient (Corr), and is then compared with that of inverse distance weighting (IDW) and hypsometric methods (HYPS). In estimating the temperature over Jeju island, K-PRISM has the lowest bias $(-0.85)$ and RMSE (1.22), and the highest Corr (0.79) among the three methods. It captures the daily variation of observation, but tends to underestimate due to a high-discrepancy in mean altitudes between the observation stations and grid points of the $30 \mathrm{~m}$ topography. The temperature over South Korea derived from K-PRISM represents a detailed spatial pattern of the observed temperature, but generally tends to underestimate with a mean bias of -0.45 . In bias terms, the estimation ability of K-PRISM differs between grid points, implying that care should be taken when dealing with poor skill area. The study results demonstrate that K-PRISM can reasonably estimate $30 \mathrm{~m}$-resolution temperature over South Korea, and reflect topographically diverse signals with detailed structure features.
\end{abstract}

Key words: PRISM, fine-scale temperature, geographic information system, interpolation method, inverse distance weighting, hypsometric method

\section{1. 서 론}

최근 농업, 공학, 수문, 경제 등 다양한 분야에서 고 해상도 격자 기상 정보의 활용성과 중요성이 점차 증 대되고 있다(Daly et al., 2002; Daly et al., 2003). 이 러한 높은 활용성에도 불구하고, 관측된 자료로부터 고르게 분포된 장기간의 고해상도 기상정보를 얻는

\footnotetext{
*Corresponding Author: Jina Hur, Division of Earth Environmental System, Pusan National University, Busandaehak-ro, 63beon-gil, Geumjeong-gu, Busan 609-735, Korea.

Phone : +82-51-514-1932, Fax : +82-51-514-1932

E-mail : hjn586@pusan.ac.kr
}

것은 쉽지 않다. 특히 지형적으로 좁고 복잡한 우리 나라의 경우, 상대적으로 조밀한 관측망이 구축되어 있다고 하더라도 대부분의 관측소들이 전력 공급 및 유지 보수의 문제점 때문에 $300 \mathrm{~m}$ 이하의 낮은 고도 에 위치하거나 수도권 중심에 편중되어 있다(Hong et al., 2007; Im and Ahn, 2011).

이러한 관측 자료의 공간적인 제약을 극복하는 방 법으로 역학적 및 통계적 방법이 최근에 많이 연구되 고 있다(e.g., Im et al., 2005; Hong et al., 2007; Shin et al., 2008; Ahn et al., 2010; Ahn et al., 2012). 지 역 기후 모형을 이용하는 역학적 방법은 물리적 - 역 학적으로 균형 있는 자료를 생산할 수 있다는 장점을 
가진다. 하지만 이 방법은 상당한 계산 시간과 방대 한 저장 공간이 요구되며(Chen et al., 2012), 모델의 계통적 오차가 포함될 수 있다(Ahn et al., 2012)는 단 점을 가진다. 이러한 이유 때문에 격자형태의 고해상 도 기후정보를 생산하는 효율적인 방법으로 통계적 방법도자주 이용된다(e.g., Daly, 2006; Chung et al., 2009; Brunetti et al., 2013).

격자형 국지 기후자료를 통계적으로 추정하는 방법 은 격자점과 관측지점 간의 거리를 어떻게 고려하느 냐에 따라 크게 세 가지로 분류할 수 있다. 첫 번째 방법은 거리를 전혀 고려하지 않고 단지 통계적 - 물 리적 관계에만 의존하는 것으로, 여기에는 선형 - 비 선형 회귀(Schoof and Pryor, 2001)와 유사 패턴 검색 방법(Hidalgo et al., 2008) 등이 포함된다. 그러나 이 방법의 경우 격자점의 과거 기상정보에 근거하기 때 문에 격자점의 과거 기상정보가 없는 상태에서 사용 하는 것은 한계가 있다. 두 번째 방법은 기상요소의 동질성을 거리만의 함수로 계산하는 것으로, 여기에 는 Barnes기법(Barnes, 1964), Cressman기법(Cressman, 1959), 역거리가중법(Inverse Distance Weighting, IDW) (Szolgay et al., 2009) 등이 포함된다. 많은 연구자 (e.g., Brunetti et al., 2013; Daly, 2006; Daly et al., 2003)들은 동일성을 결정짓는 가장 중요한 요소가 거 리차라고 평가하지만, 인접한 지역의 지형학적 환경 도 무시할 수 없다는 결과를 제시하였다. 세 번째 방 법은 두 번째 방법에서 지형학적 정보까지 고려한 것 으로, Hypsometric기법(이하 HYPS) (Ahrens, 2003)과 PRISM (Parameter-elevation Regressions on Independent Slopes Model) (Daly et al., 1994, 2002)이 대표적이다. 특히 PRISM은 다른 기법과 비교하여 인접한 기상자 료에 대한 의존성이 상대적으로 작고 지리 특성에 대 한 의존성이 커서, 불균질하며 성긴 관측 자료로부터 고분해능 격자정보를 추정할 때 유용하게 사용 가능하다.

국내에서도 최근 몇 년 동안 남한 영역에 대한 고 해상도 기상자료의 필요성이 대두되면서 PRISM을 이 용한 격자형 기상자료 생산 방법에 대한 연구가 이루 어졌다. Hong et al. (2007)은 남한에 적합한 PRISM 기법(이하 K-PRISM)을 제시하였으며, 이를 이용하여 $5 \mathrm{~km}$ 해상도의 기온 격자자료를 생산하였다. Shin et al. (2008)과 Chung et al. (2009)은 K-PRISM을 이용하여 각각 $5 \mathrm{~km}$ 와 $270 \mathrm{~m}$ 해상도의 강수 격자자료를 생산 한 바 있다. 또한 $\operatorname{Kim}$ et al. (2012)은 $1 \mathrm{~km}$ 간격의 월 강수량을 추정하기 위하여 PRISM 모형에 Daymet 모형을 접목시킨 새로운 강수량 추정 모형을 제시하 고 분석하였다. 그러나 이러한 연구들은 $100 \mathrm{~m}$ 이상 의 해상도를 가지고 있어 빌딩 주변과 경작지 경계에 서 발생하는 국지기상의 변화를 살펴보기에는 다소 미흡하다(Rider et al., 1963), 특히 2011년 우리나라의
가구원 1 인당 평균 경지면적이 약 $71.8 \mathrm{~m} \times 71.8 \mathrm{~m}$ 임 을 고려할 때, 우리나라 농경지에서 발생하는 병해충 및 작물 생육 환경과 관련된 국지 기상을 살펴보기 위해서는 $100 \mathrm{~m}$ 이하의 고해상도 기상 정보가 필요하다.

따라서 본 연구에서는 국지기상의 이해도와 타 분 야에서의 활용 가능성을 높이기 위해 K-PRISM을 기 반으로 하여 $30 \mathrm{~m}$ 고해상도 일별 기온자료를 산출하 고자 하였다. 이를 위해 $30 \mathrm{~m}$ 해상도와 일 단위의 시 간 간격에 적합하도록 K-PRISM의 일부 요소를 수정 하였으며, 이를 기존의 방법과 비교하였다. 본 연구는 장기간의 기후값 추정에 앞서 수정된 K-PRISM 방법 을 시범적으로 2003년부터 2012년까지의 1월 기온에 적용함으로써 방법의 타당성을 검증하는 데 초점을 두었다.

\section{2. 자료 및 연구방법}

\section{1 자료}

본 연구에서는 2003년부터 2012년까지 기상청에서 관측한 1 월의 일 평균 기온 자료를 사용하였다. 이 자 료는 사용 목적에 따라 PRISM 입력자료와 검증자료 로 나눌 수 있다. Figure 1은 각 해마다 관측된 관측 지점의 수를 나타낸 것으로, 1973년부터 60 개 이상의 지상기상관측소(Automated Synoptic Observing System, $\mathrm{ASOS}$ )에서 기상 관측이 시작된 것을 볼 수 있다. 따 라서 입력 자료의 동질성을 고려하여, 향후 40년 기 후장 생산을 위해 1973년부터 관측이 시작된 60개의 $\mathrm{ASOS}$ 지점들의 자료를 PRISM의 입력 자료로 사용 하였다. 검증 자료로 사용된 기상자료는 PRISM에 사 용되지 않았던 352개의 자동기상관측지점(Automated Weather Station, AWS)에서 관측된 자료이다. 현재 수 준의 AWS 관측망이 1990년 후반부터 구축되었기 때 문에 본 연구에서는 검증 기간을 10 년으로 설정하였 다(Im and Ahn, 2011). Figure 2는 PRISM에 사용된 60 개의 $\mathrm{ASOS}$ 와 검증에 사용된 352개의 $\mathrm{AWS}$ 의 위치 를 나타낸 것이다.

고해상도 격자 고도 자료는 $30 \mathrm{~m}$ 해상도의 ASTER

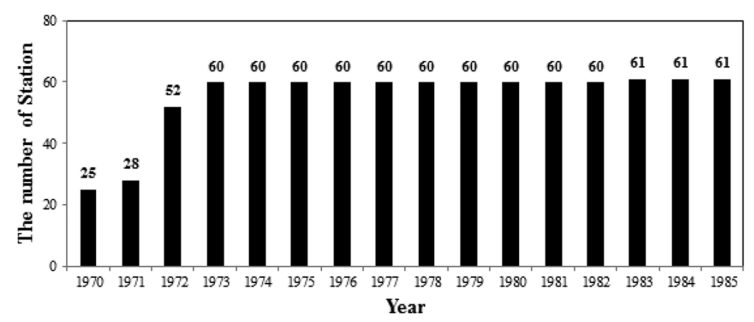

Fig. 1. The number of in-situ weather observation stations working in each year. 


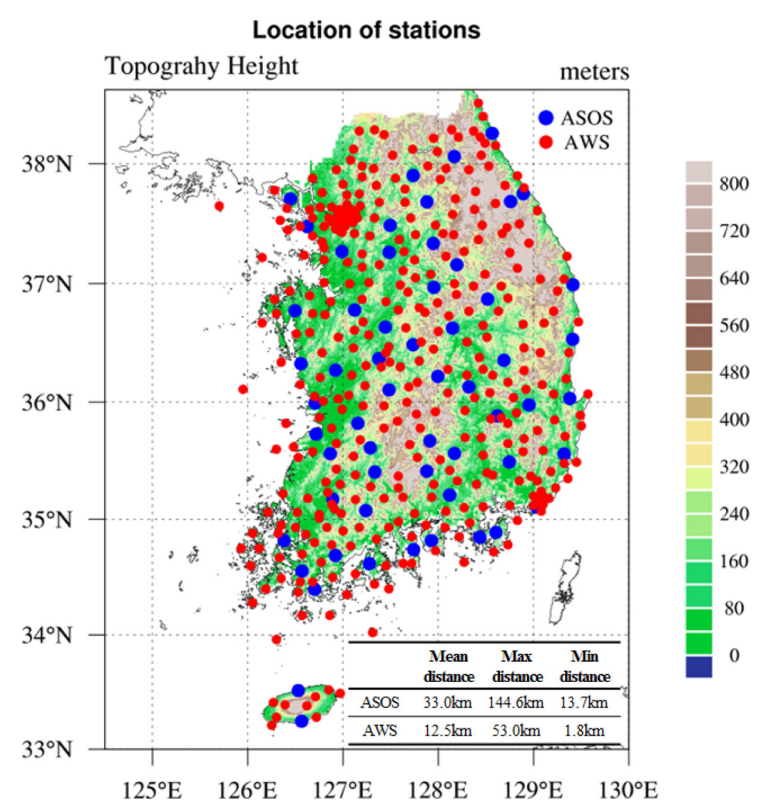

Fig. 2. Topography (m) and distribution of 60 ASOS (large dot) and 352 AWS (small dots) used in this study (ASOS are used as input data for PRISM, whereas AWS are used for validation).

Global Digital Elevation Map (GDEM) (Frey and Paul, 2012) 자료를 사용하였다(Fig. 2). 또한 이 자료를 이 용하여 남한영역의 지향면(topographic facet)과 해양 도(coastal proximity) 정보도 산출하였다.

\section{$2.2 \mathrm{~K}-\mathrm{PRISM}$ 적용 방법}

K-PRISM은 크게 네 가지 단계로 나눌 수 있다. 첫 번째는 K-PRISM에 필요한 다양한 지리정보(Geographic Information System, GIS)를 산출하는 단계이다. 이때 생산되는 정보는 남한 영역에 대한 $30 \mathrm{~m}$ 격자 간격 의 고도, 지향면, 해양도 정보이다. 즉, 산출된 자료들 은 모두 X, Y 방향으로 각각 $30 \mathrm{~m}$ 격자 간격을 가지 고 있으며, 남한 영역에 대해 총 $39,9960,000$ 개 $(19,800$ $\times 20,200)$ 의 격자점을 가진다. 두 번째는 각 격자점을
계산할 때 고려할 최소 관측점의 수와 영향 반경을 결정하는 단계이다. 이때 평균 $33.0 \mathrm{~km}$ 의 ASOS 간격 을 고려하여, 최소 관측점의 수 5 개가 영향반경 $30 \mathrm{~km}$ 에 포함되지 않으면 영향반경을 최대 $100 \mathrm{~km}$ 까지 $5 \mathrm{~km}$ 간격으로 확대하였다. 단, 고유의 기후특성들을 고려 하여 본토와 제주도는 독립적으로 계산되었다. 세 번 째 단계는 첫 번째 단계에서 생산된 GIS 자료를 바 탕으로 격자점과 관측지점 간의 지형학적 유사성을 가중치로 계산하는 것이다. 네 번째 단계는 이렇게 생 산된 가중치를 이용하여 가중 회귀식을 산출한 후, 각 격자점의 기상 값을 추정하는 것이다. 보다 자세한 설 명은 Hong et al. (2007)에서 볼 수 있다.

본 연구에서는 기존의 K-PRISM 방법을 기본적으 로 따르고 있지만, $30 \mathrm{~m}$ 의 격자 간격과 일 단위의 시 간 간격에 적합하도록 다음과 같이 첫 번째와 네 번 째 단계에서 일부 요소를 수정하였다.

\subsection{1 지향면 자료}

본 연구에서는 경사의 방향을 $\mathrm{N}$ 방향부터 $\mathrm{NW}$ 방 향까지 8 방위로 구분한 기존의 연구와 달리 $\mathrm{N}$ 방향 부터 NNW 방향까지 16 방위로 더욱 세분화하였다 (Fig. 3). 평지까지 고려하면 지향면은 총 17 가지로 구 분된다. 즉, 각 격자점을 중심으로 $\mathrm{X}$ (동서) 방향과 $\mathrm{Y}$ (남북) 방향의 거리와 고도차를 이용하여 다음과 같이 사면의 기울기 $(\theta)$ 와 경사방향(A)을 계산한다(Hong et al., 2007).

$$
\begin{aligned}
& \tan \theta=\left[(\delta \mathrm{Z} / \delta \mathrm{X})^{2}+(\delta \mathrm{Z} / \delta \mathrm{Y})^{2}\right]^{1 / 2}, \\
& \tan \mathrm{A}=(-\delta \mathrm{Z} / \delta \mathrm{Y}) /(\delta \mathrm{Z} / \delta \mathrm{X}),
\end{aligned}
$$

이때 $-\pi$ 와 $\pi$ 사이에 있는 $\mathrm{A}$ 를 좀 더 이해하기 쉽게 $0^{\circ}$ 과 $360^{\circ}$ 사이로 변환하고, Fig. 3에서와 같이 각의 크기를 기준으로 $\mathrm{A}$ 를 16 가지로 분류한다.

Figure 4 는 16 방위와 8 방위를 기준으로 구분된 지 향면들을 나타낸 것이다. 이때 색상은 Fig. 3에서 제 시한 방향의 순서대로 구성하였으며, 16 방위와 8 방위 에서 겹치는 방향들 $(\mathrm{N}, \mathrm{NE}, \mathrm{E}, \mathrm{SE}, \mathrm{S}, \mathrm{SW}, \mathrm{W}, \mathrm{NW})$ 은 모두 같은 색으로 처리하였다. 기존의 연구(e.g.,

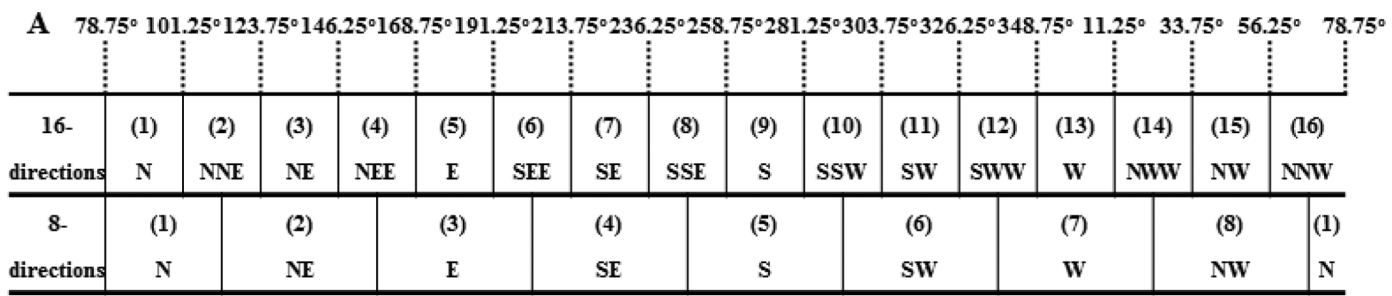

Fig. 3. Criteria for topographic facet with 16 and 8 directions. 
(a) 16-Direction

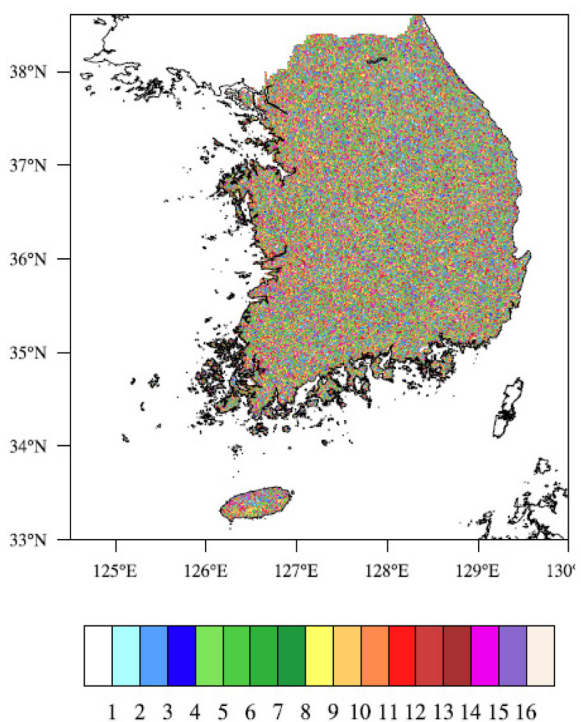

(b) 8-Direction

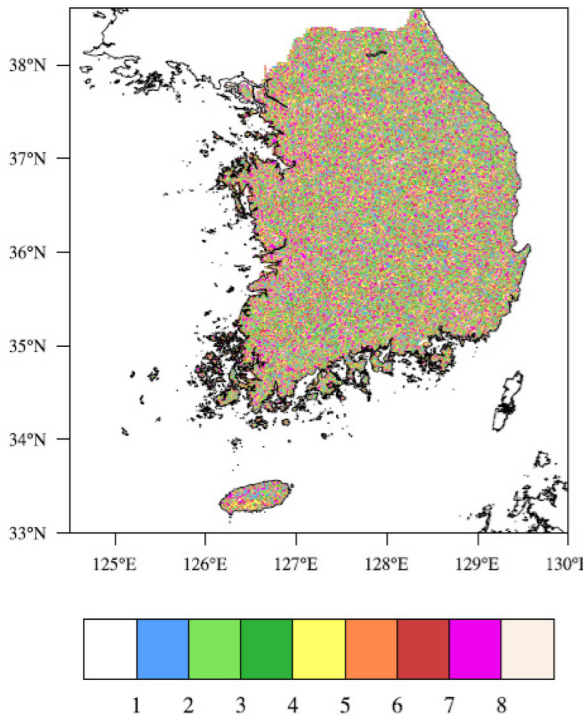

Fig. 4. Digital map of topographic facet over South Korea derived from (a) 16-directions and (b) 8-directions.

(a) 16-Direction_Jeju

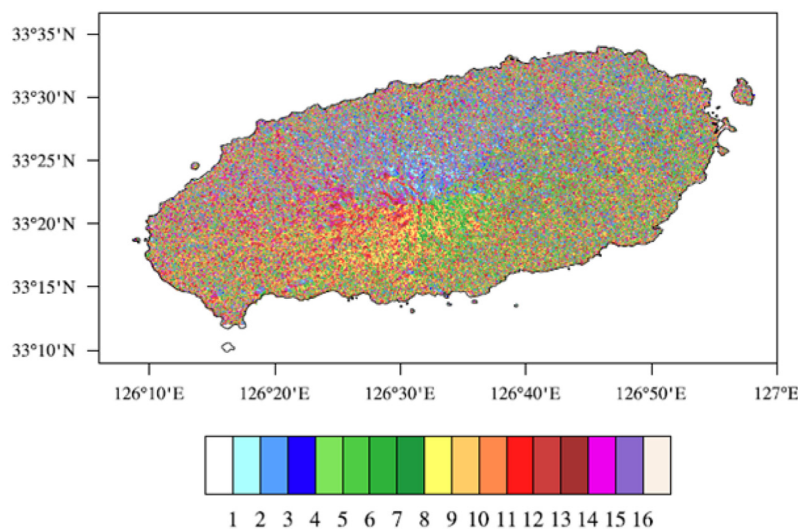

Fig. 5. Same as Fig. 4, but for Jeju island over South Korea.

Hong et al., 2007)와 유사하게 8방위로 구분된 $30 \mathrm{~m}$ 해상도의 지향면은 본토에서 지형학적 특징이 식별될 수 없을 정도로 매우 복잡하게 나타난다. 반면 제주 도는 한라산을 중심으로 사면의 방향성이 뚜렷하며 $\mathrm{N}$ 부터 $\mathrm{NW}$ 까지 다양하게 나타난다. 16 방위를 기준으로 구분된 지향면은 8 방위로 구분된 지향면과 전반적으 로 유사한 공간 패턴을 가지나, 더 세분화된 것이 특 징이다. 뚜렷한 방향성을 가진 제주도를 예로써 살펴 보면, 두 지향면은 모두 제주도 북쪽에 $\mathrm{NE}$, 남동쪽에 $\mathrm{SE}$, 서쪽에 $\mathrm{SW}$ 가 지배적으로 나타난다(Fig. 5). 단, 16 방위의 지향면은 제주도 북쪽에 $\mathrm{NE}$ 가 주도적으로 (b) 8-Direction_Jeju

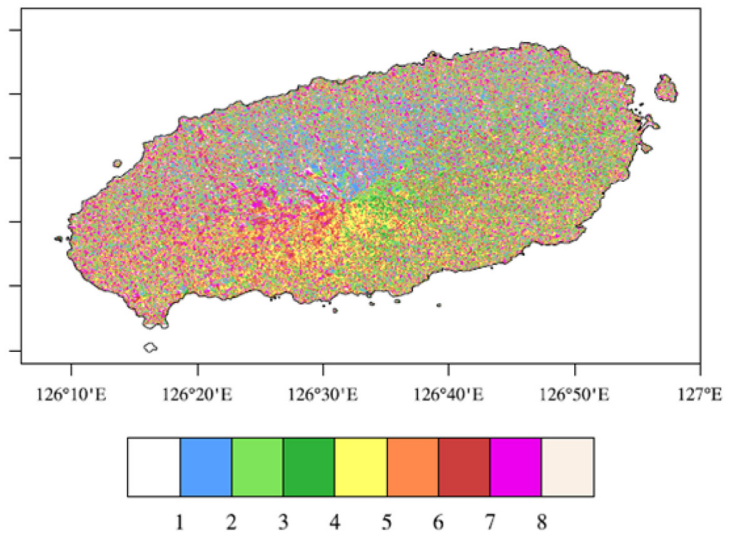

나타나던 8 방위의 지향면과는 다르게 $\mathrm{NNE}, \mathrm{NE}, \mathrm{NEE}$ 로 세분화되어 다양하게 나타난다.

\subsection{2 가중 회귀식의 기울기 한계값 설정}

본 연구에서 PRISM에 사용된 60개의 ASOS 관측 지점을 해발고도에 따라 분류해보면 Fig. 6와 같다. 60 개의 $\mathrm{ASOS}$ 중에서 1 개의 관측소(대관령)을 제외 한 59 개(약 $98 \%$ )의 관측소가 $300 \mathrm{~m}$ 이하에 위치해 있다. 이 비율은 Hong et al. (2007)에서 제시한 87\% 보다 $11 \%$ 더 큰 값이다. 또한 $300 \mathrm{~m}$ 이하에 위치하 는 59 개의 관측소 중에서도 약 $76 \%$ 가 $100 \mathrm{~m}$ 이하의 


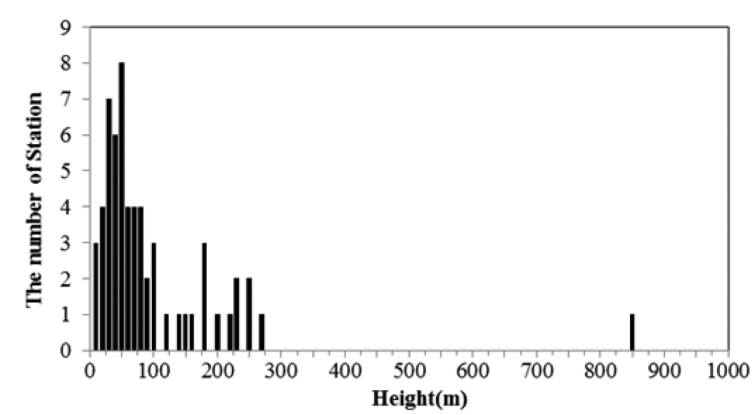

Fig. 6. The number of ASOS with the height.

저지대에 위치한다. 이는 본 연구에서 기상값 추정을 위해 고려된 관측지점들이 고도에 따라 매우 불균일 하게 분포하며, 결국 일부 격자점에서 회귀식의 기울 기 $\left(\hat{\beta}_{1}\right)$ 가 비정상적인 값으로 산출될 가능성이 높다 는 것을 의미한다. 이를 해결하기 위해서 본 연구에 서도 Hong et al. (2007)와 같이 관측자료에서 유도 된 평균 기온 감률을 기준으로 회귀식의 기울기를 제 한하였다(Fig. 7). 단, 월 평균 기온 감률을 고려한 Hong et al. (2007)과는 다르게, 일 간격을 고려하여 1973년부터 2012년까지 40년 평균된 일 평균 기온 감률과 표준편차 $(\mathrm{Std})$ 를 계산하였으며, 작은 변동성

\section{Temperature lapse rate}

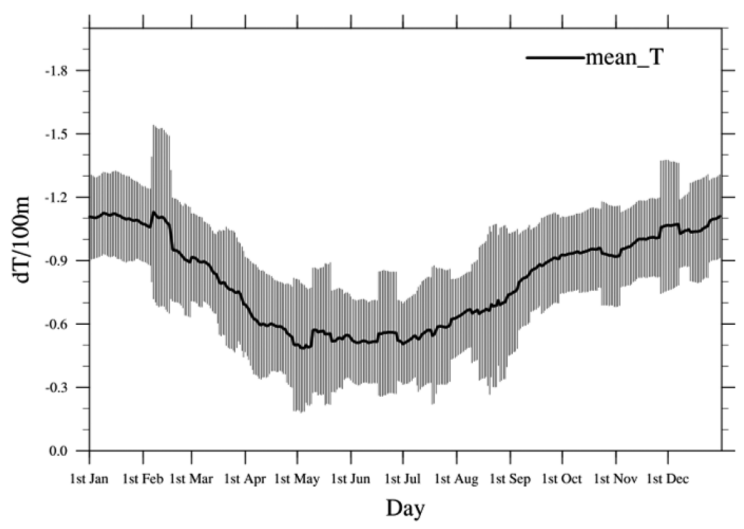

Fig. 7. Daily mean of temperature lapse rate averaged over 40 years from 1973 to 2012 and their 0.5 standard deviations (10-day moving average is applied.).

Table 1. Change in $\hat{\beta}_{1}$ according to each condition.

\begin{tabular}{ccc}
\hline & Conditions & $\hat{\beta}_{1}$ \\
\hline \hline 1 & $\hat{\beta}_{1}<-0.5 \times$ Std & $\hat{\beta}_{1}=-0.5 \times$ Std \\
2 & $-0.5 \times$ Std $\leq \hat{\beta}_{1} \leq+0.5 \times$ Std & $\hat{\beta}_{1}=\hat{\beta}_{1}$ \\
3 & $\hat{\beta}_{1}>+0.5 \times$ Std & $\hat{\beta}_{1}=+0.5 \times$ Std \\
\hline
\end{tabular}

을 제거하기 위하여 10 일 이동평균을 수행하였다. 일 평균 기온 감률의 $+0.5 \times \mathrm{Std}$ 와 $-0.5 \times \mathrm{Std}$ 를 각각 회 귀식 기울기의 최고값과 최저값으로 설정하였다(Table 1). 따라서 본 연구에서는 일별로 기울기의 최소값과 최대값을 제한함으로써 기온 감률의 일 변동성을 고 려하였다.

\section{3 검증 방법}

고해상도 기온 추정 방법의 타당성을 살펴보기 위 하여 제 3 절에서는 16 방위 지향면을 이용한 K-PRISM (이하 16Dir-K-PRISM)로 추정된 1월의 일 평균 기온 을 기존 연구에서 사용된 8 방위 지향면을 이용한 $\mathrm{K}-$ PRISM (이하 8Dir-K-PRISM), IDW, HYPS 방법들로 추정된 기온들과 비교 분석하였다. 검증을 위해 공간 적인 분포도, 시계열과 같은 정성적인 방법과 편이 (Bias), 오차제곱근(Root Mean Square Error, RMSE), 상관 계수(Correlation Coefficient, Corr) 등의 정량적 인 방법이 이용되었다. 본 연구에서 비교하기 위해 사 용된 IDW와 HYPS 방법은 다음과 같다.

$$
\begin{aligned}
& \text { IDW: } T=\left(\sum_{i=1}^{n} T s_{i} / d_{i}^{2}\right) /\left(\sum_{i=1}^{n} 1 / d_{i}^{2}\right), \\
& \text { HYPS: } T=\left[\left(\sum_{i=1}^{n} T s_{i} / d_{i}^{2}\right) /\left(\sum_{i=1}^{n} 1 / d_{i}^{2}\right)\right] \\
& +\left[Z-\left(\sum_{i=1}^{n} Z s_{i} / d_{i}^{2}\right) /\left(\sum_{i=1}^{n} 1 / d_{i}^{2}\right)\right] \Gamma, \\
& \Gamma=-1 \times \mid 0.00688 \\
& +0.0015 \cos (0.0172(\text { Julian day }-60)) \mid .
\end{aligned}
$$

여기서 $T$ 와 $Z$ 는 추정하고자 하는 특정 격자점의 기 온과 고도이며, $\Gamma$ 는 경험적 기온 감률(Yun et al., 2000) 이다. $T s_{i}$ 와 $Z s_{i}$ 는 특정 격자점을 중심으로 영향 반경 $(100 \mathrm{~km})$ 안에 포함된 $\mathrm{n}$ 개의 관측점 중에서 $\mathrm{i}$ 번째 관 측점의 기온과 고도를 의미한다.

\section{3. 연구결과}

\section{1 제주도 지역에 대한 K-PRISM의 적용}

$16 \mathrm{Dir}-\mathrm{K}-\mathrm{PRISM}$ 을 남한 전체 영역에 적용하기에 앞서, 지형적 특성이 뚜렷한 제주도 지역에 먼저 적 용하고 2012년 1월 사례 기간에 대해 분석하였다. 제주도는 한라산을 중심으로 하는 원추형의 지형을 가지고 있어, 고도가 높은 중심부에서 상대적으로 낮 은 기온이, 고도가 낮은 주변부에서 상대적으로 높 은 기온이 나타나는 특징이 있다. 이러한 이유로 제 주도는 고도, 지향면, 해안도와 같은 지리 정보나 추 

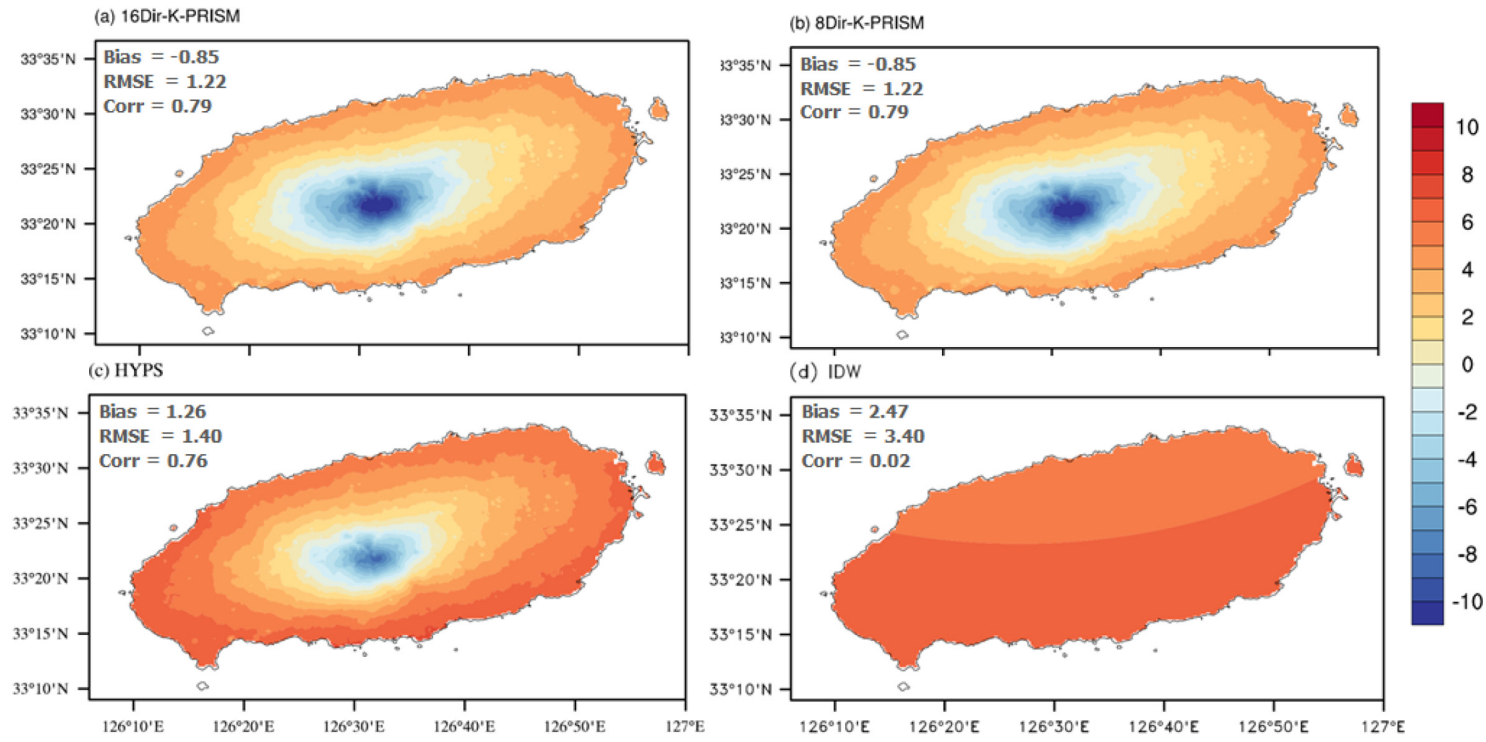

Fig. 8. Spatial distribution of daily mean temperatures $\left({ }^{\circ} \mathrm{C}\right.$ ) in January 2012 derived from (a) 16Dir-K-PRISM (upper left), (b) 8-Dir-K-PRISM (upper right), (c) HYPS (lower left), (d) IDW (lower right) over Jeju island in South Korea (Skill scores are calculated at each AWS site over Jeju island and averaged).

정된 기온 자료를 정성적으로 평가하기에 좋은 지역 이다.

Figure 8은 16Dir-K-PRISM, 8Dir-K-PRISM, IDW, HYPS 방법으로 추정된 2012년 1월의 일 평균 기온 분포도와 각 방법의 산출수준을 나타낸 것이다. 고도 를 고려하는 16Dir-K-PRISM, 8Dir-K-PRISM, HYPS 는 한라산을 중심으로 낮은 기온을 산출하고 있지만, 거리만을 고려하는 IDW는 고도에 따른 기온 변이 를 잘 나타내지 못하고 있다. 특히 본 연구에서는 제 주도의 기온 분포도를 추정하기 위해서 해발고도 $60 \mathrm{~m}$ 이내에 위치하고 있는 단지 2개의 $\operatorname{ASOS}$ (제주 도, 서귀포) 자료가 사용되었기 때문에, 거리만의 함 수로 고도의 편차가 큰 제주도의 기온 분포를 추정 하는 것은 어렵다. 고도를 고려하는 세 가지의 방법 중에서 K-PRISM을 근거로 한 $16 \mathrm{Dir}-\mathrm{K}-\mathrm{PRISM}$ 와 8Dir-K-PRISM은 고도에 따른 기온 감소 경향을 더 크게 고려함으로써 기온을 한라산의 중심에서 HYPS 보다 더 낮게 모의한다. 이로 인해 K-PRISM을 기반 으로 하는 두 방법은 -0.85 의 음의 Bias가 나타나는 반면, HYPS와 IDW는 1.2 이상의 양의 Bias가 나타 난다. 산출 수준을 좀 더 정량적으로 살펴보면, $16 \mathrm{Dir}-$ K-PRISM과 8Dir-K-PRISM은 2012년 1월 제주도 지 역에 대해 가장 낮은 $\mathrm{BIAS}(-0.85), \mathrm{RMSE}(1.22)$ 와 가장 높은 $\mathrm{CORR}$ (0.79)을 가지고 있어 기온 추정 능력이 다른 기법보다 상대적으로 높은 것으로 나타 났다.

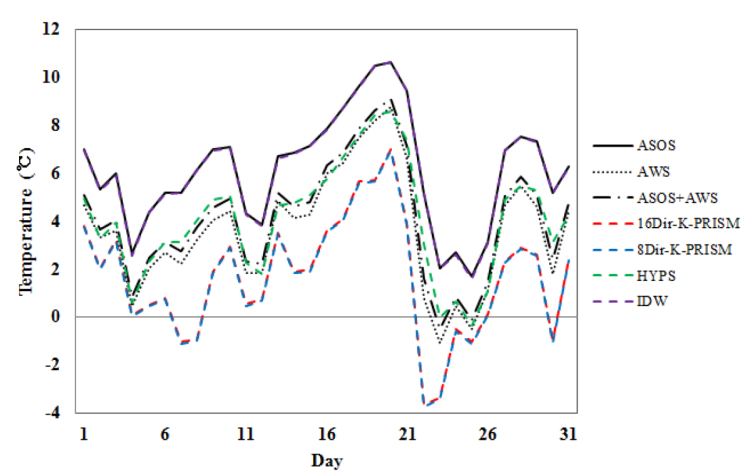

Fig. 9. Daily mean temperature series in January 2012 derived from ASOS, AWS, ASOS+AWS, 16Dir-K-PRISM, 8Dir-K-PRISM, HYPS, IDW over Jeju island in South Korea.

시간 변동성에 대한 공간 추정 기법들의 모사 능력 을 살펴보기 위해 사례 기간에 제주도에서 관측된 일 평균 기온(ASOS, $\mathrm{AWS}, \mathrm{ASOS}+\mathrm{AWS})$ 과 추정된 일 평 균 기온(16Dir-K-PRISM, 8Dir-K-PRISM, IDW, HYPS) 의 시계열을 비교하고 분석하였다(Fig. 9). ASOS에서 관측된 기온은 $\mathrm{AWS}$ 를 포함하여 다른 기온 자료보다 상대적으로 높게 나타나는데, 그 이유는 Fig. 2에서 볼 수 있듯이 대부분의 관측지점이 평균 해발 고도 $35.15 \mathrm{~m}$ (남한 평균: $92.1 \mathrm{~m}$ )로 저지대에 위치하기 때 문이다. 즉, $\mathrm{AWS}$ 지점들이 평균 해발 고도 $198.7 \mathrm{~m}$ 
(남한 평균: $117.0 \mathrm{~m}$ )로 $\mathrm{ASOS}$ 와 비교하여 상대적으로 고지대에 분포하기 때문에 $\mathrm{AWS}$ 와 $\mathrm{ASOS}+\mathrm{AWS}$ 의 평균 기온은 $\mathrm{ASOS}$ 와 유사한 시간 패턴을 가지면서 $\mathrm{ASOS}$ 보다 약 2.0도 이상 낮게 나타난다. 추정된 기 온들을 살펴보면, 고도를 고려하지 않는 IDW는 ASOS 와, 거리와 고도만 고려하는 HYPS는 AWS 및 $\mathrm{AWS}+\mathrm{ASOS}$ 와 유사한 값으로 변동한다. $16 \mathrm{Dir}-\mathrm{K}-$ PRISM, 8Dir-K-PRISM는 관측 지점의 패턴을 잘 모 사하면서, 모든 관측 자료보다 기온을 낮게 추정한다. 이러한 기온의 차이는 관측 지점과 $30 \mathrm{~m}$ 해상도를 가 진 지형자료의 평균 고도차로 설명할 수 있다. 즉, 제주도 지역에 대한 2,332,375개(남한 육지 영역: $132,706,372$ 개) 격자점의 평균 해발 고도가 $278.6 \mathrm{~m}$ (남한 육지 평균: $139.9 \mathrm{~m}$ )로 관측 지점의 평균 고도 보다 더 높기 때문이다. 결과적으로 $16 \mathrm{Dir}-\mathrm{K}-\mathrm{PRISM}$, 8Dir-K-PRISM, HYPS는 모두 관측 지점과 격자점 간 의 고도차에 의해 절대적인 평균 기온 값을 입력 자 료인 ASOS보다 더 낮게 산출하지만, 관측의 시간 전 개 패턴을 유사하게 모사한다.

\section{2 남한 영역에 대한 K-PRISM의 적용}

본 절에서는 제주도의 사례 분석에서 정성적 및 정 량적으로 산출 수준이 높다고 평가된 16Dir-K-PRISM 와 8Dir-K-PRISM을 이용하여 남한 영역에 대한 $30 \mathrm{~m}$ 기온 자료를 2003년부터 2012년까지 산출하고 분석
Table 2. Skill scores of daily mean temperature in January derived from 16Dir-K-PRISM and 8Dir-K-PRISM for 10 years from 2003 to 2012 (Skill scores are calculated at each AWS site over South Korea and averaged).

\begin{tabular}{cccccccc}
\hline \multirow{2}{*}{$\begin{array}{c}\text { S. Korea } \\
(\text { Mean T) }\end{array}$} & \multicolumn{3}{c}{ 16Dir-K-PRISM } & & \multicolumn{3}{c}{ 8Dir-K-PRISM } \\
\cline { 7 - 8 } & Bias & RMSE & Corr & & Bias & RMSE & Corr \\
\hline \hline 2003 & -0.70 & 2.13 & 0.82 & & -0.70 & 1.62 & 0.80 \\
2004 & -0.59 & 1.96 & 0.77 & & -0.57 & 1.50 & 0.75 \\
2005 & -0.24 & 1.70 & 0.81 & & -0.24 & 1.43 & 0.79 \\
2006 & -0.43 & 1.77 & 0.77 & & -0.41 & 1.77 & 0.75 \\
2007 & -0.67 & 1.96 & 0.74 & & -0.62 & 1.92 & 0.72 \\
2008 & -0.37 & 1.71 & 0.80 & & -0.36 & 1.72 & 0.77 \\
2009 & -0.48 & 1.99 & 0.81 & & -0.49 & 2.00 & 0.80 \\
2010 & -0.43 & 2.10 & 0.84 & & -0.43 & 2.08 & 0.82 \\
2011 & -0.26 & 1.92 & 0.82 & & -0.25 & 1.89 & 0.79 \\
2012 & -0.33 & 1.76 & 0.81 & & -0.32 & 1.74 & 0.78 \\
\hline Average & -0.45 & 1.90 & 0.80 & & -0.44 & 1.77 & 0.78 \\
\hline
\end{tabular}

하였다. Figure 10은 2003년부터 2012년까지 10년 동 안 평균된 1 월의 일 평균 기온 분포도를 나타낸 것이 다. 두 방법으로 산출된 일 평균 기온들은 유사한 공 간 패턴으로 남한의 상세한 지형적 특징을 모두 잘 반영하고 있다. 즉, 두 방법은 주요 산맥을 따라 기온 을 낮게, 저위도 및 해안가 주변에 기온을 높게 모사 하는 등 남한의 복잡한 지형 구조 및 기온 분포 특성 (a) 16Dir-K-PRISM

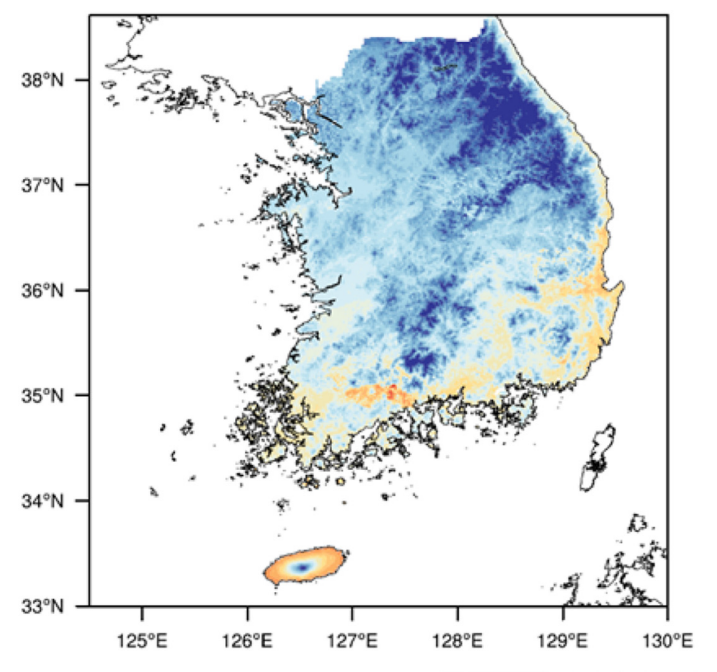

(b)8Dir-K-PRISM

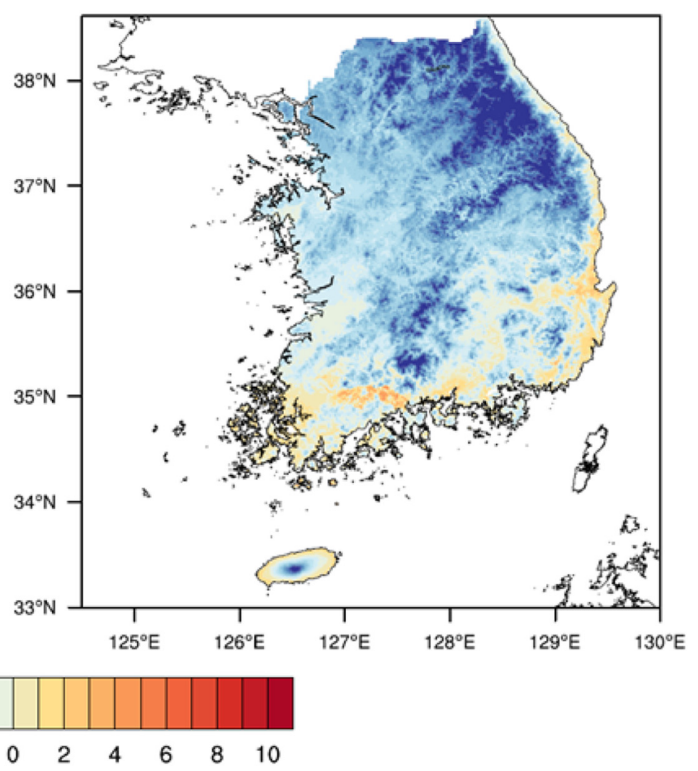

Fig. 10. Spatial distribution of daily mean temperature $\left({ }^{\circ} \mathrm{C}\right)$ in January averaged over 10 years from 2003 to 2012 derived from 16Dir-K-PRISM (left) and 8Dir-K-PRISM (right) over South Korea. 
(a) 16Dir-K-PRISM

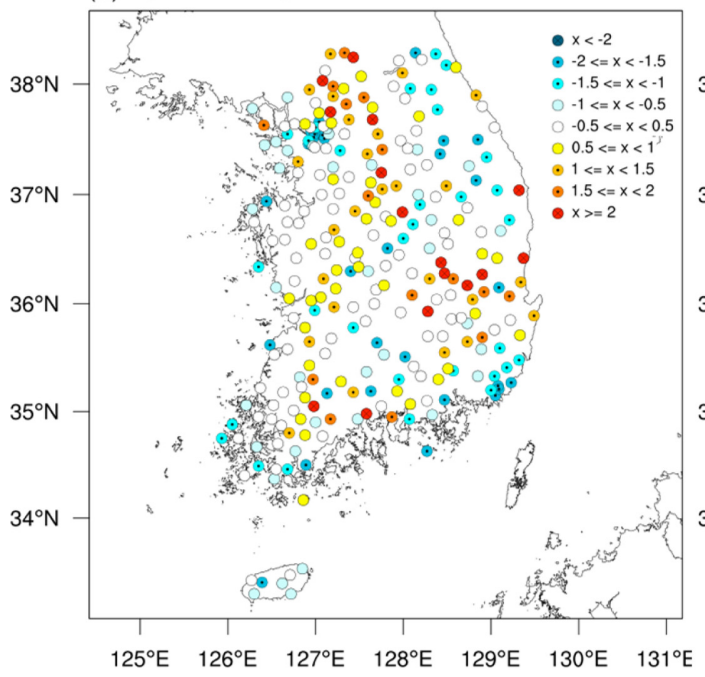

(b) 8Dir-K-PRISM

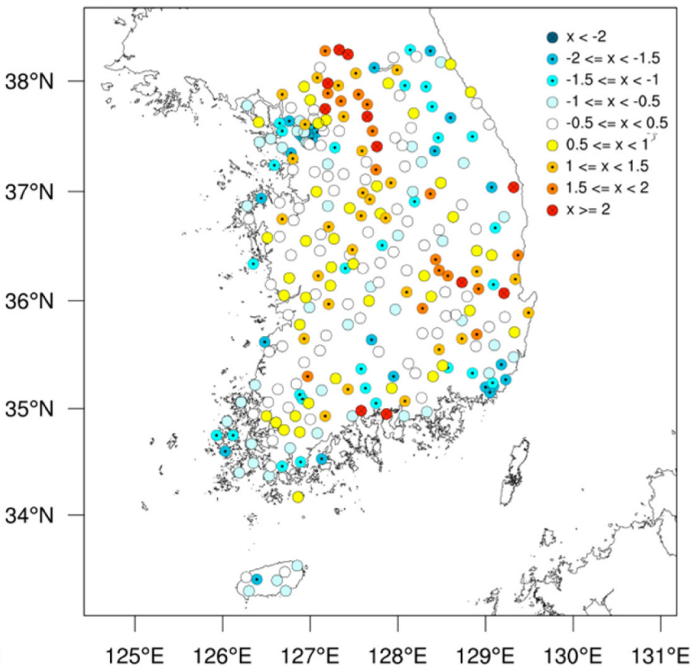

Fig. 11. Spatial distribution of daily mean temperature biases in January 2012 derived from 16Dir-K-PRISM (left) and 8Dir-KPRISM (right) (Biases are calculated at 352 AWS sites over South Korea).

을 상세하게 잘 나타내고 있다. 16Dir-K-PRISM과 8Dir-K-PRISM이 남한 평균 기온을 각각 -3.3 와 -3.8 로 산출함으로써, 8Dir-K-PRISM이 16Dir-K-PRISM보 다 약 0.5 도 낮게 기온을 추정하였다.

산출 수준을 좀 더 정량적으로 비교하기 위해 본 연구에서 PRISM 방법으로 산출된 기온과 352 개의 $\mathrm{AWS}$ 에서 관측된 기온간의 Bias, RMSE, Corr을 연도 별로 살펴보았다(Table 2). 평균적으로 16Dir-K-PRISM 와 8 Dir-K-PRISM은 Bias가 각각 -0.45 와 -0.44 , RMSE 가 각각 1.90 과 1.77 , Corr가 각각 0.80 과 0.78 로 나 타났다. 이 결과는 Hong et al. (2007)에서 제시한 1 월 평균 Bias (0.014), RMSE (0.939)보다 높고, Corr (0.952)보다 낮다. 이러한 차이는 크게 두 가지로 설 명될 수 있다. 첫 번째는 기온 추정에 사용된 관측 자료에 대한 차이이다. 즉, 선행 연구에서는 ASOS뿐 만 아니라 AWS의 자료를 PRISM의 입력 자료로 사 용하였기 때문에 격자 기온을 추정할 때 더 많은 양 질의 정보가 고려되었다는 것이다. 두 번째는 생산된 기상 자료의 시간 간격에 대한 차이이다. 본 연구에 서는 일별 기상 정보를 산출한 반면, 홍기옥 등(2007) 은 월별 기상 정보를 산출하였기 때문에 정량적으로 다르게 평가될 수 있다는 것이다. 물론, 이러한 두 가 지 이유 이외에도 해상도, 분석 기간, 고도 자료의 종 류 등 다양한 인자들도 다른 평가 결과를 야기하는 요소가 될 수 있다.

16Dir-K-PRISM와 8Dir-K-PRISM은 모두 평균적으 로 기온을 과소 추정하는 경향이 있지만, 관측의 공 간 변화 패턴을 전반적으로 잘 모사하였다. Bias와
RMSE가 낮고, Corr이 높으면 산출 수준이 높다는 것 을 고려할 때, Bias와 RMSE 측면에서는 8Dir-KPRISM이, Corr 측면에서는 16Dir-K-PRISM이 더 산 출 수준이 높다고 평가할 수 있다. 이는 두 기법이 같 은 산출 수준을 가진다고 평가된 제주도 사례 분석과 는 다소 차이가 나는 결과로, 지리적 위치에 따라 PRISM의 산출 수준이 다르다는 것을 암시한다. 따라 서 PRISM의 산출 수준을 지역별로 살펴보기 위해 $\mathrm{Bias}$ 를 AWS 관측 지점별로 분석하였다.

Figure 11은 제주도 사례기간과 같은 2012년 1월에 대한 $\mathrm{Bias}$ 를 관측 지점별로 나타낸 것이다. 두 기법은 평균 $\mathrm{Bias}$ 가 -0.33 과 -0.32 로, 약 $40 \%$ 의 관측 지점에 서 관측과 $\pm 1^{\circ} \mathrm{C}$ 이내의 차이로 일 평균 기온을 추정 하고 있다. 그러나 $16 \mathrm{Dir}-\mathrm{K}-\mathrm{PRISM}$ 는 101 개의 관측소 에서 $\pm 1 \sim 2^{\circ} \mathrm{C}$ 의 Bias가, 55 개의 관측소에서 $\pm 2^{\circ} \mathrm{C}$ 이 상의 Bias가 나타나는 반면, 8Dir-K-PRISM는 101개 와 49 개의 관측소에서 각각 $\pm 1 \sim 2^{\circ} \mathrm{C}$ 와 $\pm 2^{\circ} \mathrm{C}$ 이상의 $\mathrm{Bias}$ 가 나타났다. 두 기법에서 산출된 $\mathrm{BIAS}$ 는 $2.73^{\circ} \mathrm{C}$ 으로 충청북도 단양군에 위치하는 영춘 지점에서 가 장 큰 차이가 나타났다. 이 지점은 남한강과 태화산 이 인접해 있는 지형적으로 복잡한 지역에 위치한다. 이는 Bias가 공간적으로 불균일하다는 것을 의미하며, 결과적으로 PRISM의 산출 수준이 각 방법에 따라 각 격자점별로 다르다는 것을 나타낸다. 특히 Bias가 높 은 지점들은 주변 관측 지점들의 부재와 복잡한 지형 적 특성을 가지고 있는 곳으로, 상대적으로 해안가보 다 내륙에 많이 위치한다. 따라서 이 지점들은 분석 시 유의할 필요가 있다. 


\section{4. 요약 및 결론}

본 연구에서는 K-PRISM을 이용하여 남한 영역에 대해 $30 \mathrm{~m}$ 의 수평 해상도를 가지는 2003년부터 2012 년까지의 1 월 일 평균 기온을 추정하였다. 또한 $30 \mathrm{~m}$ 의 격자 간격과 일 단위의 시간 간격에 적합하도록 지향면 및 회귀식 기울기 한계값 등을 수정한 K-PRISM 방법을 제시하고, 기존의 방법들과 비교함으로써 방 법의 적합성을 검증하였다. 여기서 K-PRISM의 입력 자료와 검증 자료로 60 개의 $\mathrm{ASOS}$ 와 352 개의 $\mathrm{AWS}$ 의 일별 기온 자료가 각각 독립적으로 사용되었다.

K-PRISM을 남한 전체 영역에 적용하기에 앞서, 지 형적 특성이 뚜렷한 제주도 지역에 먼저 적용하고 2012년 1월 사례 기간에 대해 분석하였다. 분석한 결 과, $16 \mathrm{Dir}-\mathrm{K}-\mathrm{PRISM}$ 와 $8 \mathrm{Dir}-\mathrm{K}-\mathrm{PRISM}$ 은 IDW와 HYPS 보다 고도에 따른 기온 감소 경향을 더 크게 고려하 여 한라산 중심의 주변 기온을 더 낮게 추정하였다. 특히 K-PRISM을 기반으로 하는 두 기법은 가장 낮 은 $\mathrm{BIAS}(-0.85), \mathrm{RMSE}$ (1.22)와 가장 높은 $\mathrm{CORR}$ (0.79)을 가지고 있어 제주도지역에 대한 기온 추정 능력이 다른 기법보다 상대적으로 높은 것으로 나타 났다. 관측 평균 값과 비교하여 $\mathrm{IDW}$ 는 $\mathrm{ASOS}$ 와, HYPS 는 AWS 및 AWS+ASOS와 유사하게, 16Dir-K-PRISM, $8 \mathrm{Dir}-\mathrm{K}-\mathrm{PRISM}$ 는 AWS 보다 낮게 평균 기온 값을 산 출하였으며, 네 방법 모두 관측의 시간 전개 패턴을 유사하게 추정하였다.

제주도 사례 분석에서 정성적 및 정량적으로 산출 수준이 높다고 평가된 16Dir-K-PRISM와 8Dir-K-PRISM 을 이용하여 남한 영역에 대한 $30 \mathrm{~m}$ 기온 자료를 2003 년부터 2012년까지 산출하고 분석하였다. 두 방법은 모두 남한의 복잡한 지형 구조 및 기온 분포 특성을 상세하게 잘 나타내었으며, 기온을 과소 추정하는 경 향이 있었다. 평균적으로 $16 \mathrm{Dir}-\mathrm{K}-\mathrm{PRISM}$ 와 $8 \mathrm{Dir}-\mathrm{K}-$ $\mathrm{PRISM}$ 은 Bias가 각각 -0.45 와 -0.44 , RMSE가 각각 1.90 과 1.77 , Corr가 각각 0.80 과 0.78 로 나타났다. 결 과적으로 $\mathrm{Bias}$ 와 RMSE 측면에서 $8 \mathrm{Dir}-\mathrm{K}-\mathrm{PRISM}$ 이, Corr 측면에서 16Dir-K-PRISM이 더 신뢰성 있는 기 법이라고 평가 되었다. 또한 산출 수준을 지역별로 살 펴보았을 때, 주변 관측 지점들의 부재와 복잡한 지 형적 특성을 가지고 있는 곳은 상대적으로 산출 수준 이 떨어졌다. 따라서 각 방법에 따른 격자점의 산출 수준 불균일을 고려하여, Bias가 높은 지역을 해석할 때는 신중할 필요가 있다.

본 연구에서는 K-PRISM을 이용한 $30 \mathrm{~m}$ 격자 간격 의 남한 영역에 대한 일 기온을 추정함으로써, 초고 해상도에 대한 일별 기온 추정 가능성을 살펴보았다. 그러나 10 년 동안 1 월의 일 평균 기온만을 추정하고 검증하였을 뿐 아니라 민감도 실험 없이 K-PRISM의
가중치 함수를 그대로 사용하였기 때문에 방법의 적 합성을 검증하기 위해서는 추가적인 연구가 필요하다. 향후 지속적인 연구와 기후 자료 생산을 통해 보다 신뢰성 있는 $30 \mathrm{~m}$ 격자 간격의 40년 기온 기후장을 생산할 계획이다. 이렇게 생산된 다양한 계절에 대한 일별 기온 자료는 기후 민감도가 높은 농업, 임업 등 다양한 분야에서 유용하게 활용될 수 있을 것으로 생 각된다.

\section{감사의 글}

본 성과물은 농촌진흥청 연구사업(과제번호: PJ009353) 의 지원에 의해 수행되었습니다.

\section{REFERENCES}

Ahn, J.-B., J. Hur, and K.-M. Shim, 2010: A simulation of agro-climate index over the Korean Peninsula using dynamical downscaling with a numerical weather prediction model. Korean J. Agric. For. Meteorol., 12, 1-10 (in Korean with English abstract).

, J. Lee, and E.-S. Im, 2012: The reproducibility of surface air temperature over south Korea using dynamical downscaling and statistical correction. $J$. Meteor. Soc. Japan, 90, 493-507.

Ahres, C. D., 2003: Meteorology today: An introduction to weather, climate, and the environment, 7th edition, Brooks-Cole-Thomson Learning: Pacific Grove, CA.

Brunetti, M., M. Maugeri, T. Nanni, C. Simolo, and J. Spinoni, 2013: High-resolution temperature climatology for Italy: interpolation method intercomparison. Int. J. Climatol., doi: 10.1002/joc.3764.

Chen, H., C.-Y. Xu, and S. Guo, 2012: Comparison and evaluation of multiple GCMs, statistical downscaling and hydrological models in the study of climate change impacts on runoff. J. Hydrol., 434-435, 36-45.

Chung, U. K. Yun, K.-S. Cho, J. H. Yi, and J. I. Yun, 2009: The PRISM-based rainfall mapping at an enhanced grid cell resolution in complex terrain. Korean $J$. Agric. For. Meteorol., 11, $72-78$ (in Korean with English abstract).

Daly, C., R. P. Neilson, and D. L. Phillips, 1994: A statistical-topograhic model for mapping climatological precipitation over mountainous terrain, J. Appl. Meteor, 33, 140-158.

, W. P. Gibson, G. H. Taylor, G. L. Johnson, and P. Pasteris, 2002: A knowledge-based approach to the statistical mapping of climate. Clim. Res., 22, 99-113.

, E. H. Helmer, and M. Quiñones, 2003: Mapping the climate of PUERTO RICO, VIEQUES and CUL- 
EBRA. Int. J. Climatol., 23, 1359-138.

,2006: Guidelines for assessing the suitability of spatial climate data sets. Int. J. Climatol., 26, 707721.

Frey, H., and F. Paul, 2012: On the suitability of the SRTM DEM and ASTER GDEM for the compilation of topographic parameters in glacier inventories. Int. J. Appl. Earth Observ. Geoinform., 18, 480-490.

Hidalgo, H. G., M. D. Dettinger, and D. R. Cayan, 2008: Downscaling with constructed analogues: Daily precipitation and temperature fields over the United States, California Climate Change Center, 48 [avaliable at http://tenaya.ucsd.edu/wawona-m/downscaled/ supporting_materials/CEC-500-2007-123.pdf].

Hong, K.-O., M.-S. Suh, D.-K. Rha, D.-H. Chang, C. Kim, and M.-K. Kim, 2007: Estimation of high resolution gridded temperature using GIS and PRISM. J. Korean Meteorol. Soc., Atmos., 17, 255-268 (in Korean with English abstract).

Im, E.-S., and J.-B. Ahn, 2011: On the elevation dependency of present-day climate and future change over Korea from a high resolution regional climate simulation. J. Meteor. Soc. Japan, 89, 89-100.

W.-T. Kwon, and J.-B. Ahn, 2005: Downscaling of winter river-basin precipitation using a neural net- work. J. Korean Meteorol. Soc., Atmos., 41, $89-99$ (in Korean with English abstract).

Kim, J. P., G. Kim, and W.-S. Lee, 2012: Estimation of monthly areal precipitation using Daymet and PRISM. J. Korean Soc. Hazard Mitigation, 12, 83-90 (in Korean with English abstract).

Rider, N. E., J. R. Philip, and E. F. Bradley, 1963: The horizontal transport of heat and moisture-a micrometeorological study. Quart. J. Roy. Meteor. Soc., 89, 506531.

Schoof, J. T., and S. C. Pryor, 2001: Downscaling temperature and precipitation: a comparison of regressionbased methods and artificial neural networks. Int. J. Climatol., 21, 773-790.

Shin, S.-C., M.-K. Kim, M.-S. Suh, D.-K. Rha, D.-H. Jang, C.-S. Kim, W.-S. Lee, and Y.-H. Kim, 2008: Estimation of high resolution gridded precipitation using GIS and PRISM. J. Korean Meteorol. Soc., Atmos., 18, 71-81 (in Korean with English abstract).

Yun, J.-I., J.-Y. Choi, Y.-K. Yoon, and U. Chung, 2000: A spatial interpolation model for daily minimum temperature over mountainous regions. Korean J. Agric. For. Meteorol., 2, 175-182 (in Korean with English abstract). 